\title{
Mechanochemical cocrystal formation: Insights into polymorph control
}

\author{
F. Emmerling \\ ${ }^{1}$ Federal Institute for Materials Research and Testing (BAM), Richard-Willstätter-Str. 11, D-12489 Berlin, Germany \\ franziska.emmerling@bam.de
}

Different crystallization and screening techniques have been developed for the discovery of new multicomponent molecular crystals. Exploring the polymorphic space for a given organic molecule typically includes searches across well-defined conditions, among other solvents, additives, and temperature. In recent years, especially mechanochemistry has been used intensively for the screening for new solid forms and as a promising, alternative method for accessing new polymorphs of active pharmaceutical ingredients (APIs) and API-cocrystals. [1-2] The ever-increasing interest in this method is contrasted by a still limited mechanistic understanding of the mechanochemical reactivity and selectivity. Furthermore, the influence of liquids used during the grinding on the polymorphic outcome is still far from being understood. Time-resolved in situ investigations of milling reactions provide direct insights in the underlying mechanisms. [3-5] We recently introduced different setups enabling in situ investigation of mechanochemical reactions using synchrotron XRD combined with Raman spectroscopy and thermography allowing to detect crystalline, amorphous, eutectic, and liquid intermediates. In this contribution, we will discuss our recent results investigating the formation of (polymorphic) cocrystals and salts, thereby elucidating the influence of solvents and seeds on the polymorph formation. [6-8] Our results indicate that in situ investigation of milling reactions offer a new approach to tune and optimize mechanochemical processes.

[1] James, S. L., Adams, C. J., Bolm, C., Braga, D., Collier, P., Friscic, T., Grepioni, F., Harris, K. D. M., Hyett, G., Jones, W.et al.(2012) Chem. Soc. Rev., 41, 413.

[2] Hasa, D., Jones, W. (2017). Adv. Drug. Deliv. Rev. 117, 147.

[3] Batzdorf, L., Fischer, F., Wilke, M., Wenzel, K. J., Emmerling, F. (2015) Angew. Chem. Int. Edit. 54, 1799.

[4] Kulla, H., Wilke, M., Fischer, F., Rollig, M., Maierhofer, C., Emmerling, F. (2017) Chem. Commun. 53, 1664.

[5] Kulla, H., Haferkamp, S., Akhmetova, I., Rollig, M., Maierhofer, C., Rademann, K., Emmerling, F. (2018) Angew. Chem. Int. Edit., 57, 5930.

[6] Kulla, H., Michalchuk, A. A. L., Emmerling, F. (2019) Chem. Commun. 2019, 55, 9793.

[7] Kulla, H., Becker, C., Michalchuk, A. A. L., Linberg, K., Paulus, B. \& Emmerling, F. (2019). Cryst. Growth. Des. $19,7271$.

[8] Linberg, K., Ali, N. Z., Etter, M., Michalchuk, A. A. L., Rademann, K. \& Emmerling, F. (2019). Cryst. Growth. Des. 19, 6822.

Keywords: Cocrystals; mechanochemistry; in situ, polymorphism, time-resolved 